\title{
Does Asymmetric Information Cause the Home Equity Bias?*
}

\author{
Claudio Bravo-Ortega \\ World Bank \\ and \\ Department of Economics \\ Universidad de Chile \\ Comments welcome
}

\begin{abstract}
The home equity bias is one of the many puzzles existing in international finance. This puzzle is characterized by the concentration of domestic equity in any investor's portfolio, which is in contradiction with the benchmark of full diversification in a world mutual fund. Based on Admati's (1985) and Gehrig's (1993) noisy rational expectation models, this paper attempts to explain the effect of asymmetric information in the home equity bias puzzle. While asymmetric information helps to explain the puzzle for the case of one domestic and one foreign equity, this result relies on very restrictive assumptions. Using a model with one domestic asset and two foreign assets, I illustrate that asymmetries of information are also consistent with home equity bias reversals. One proposition generalizes these results. Simulations corroborate the main theoretical predictions of the model presented in this paper.
\end{abstract}

Keywords: Home Bias puzzle, Asymmetric Information, International Finance, General Equilibrium, Noisy Rational Expectations Model.

JEL Classification: F3,F4,D5.

${ }^{*}$ I would like to thank the comments and encouragement of Robert Anderson, George Akerlof, Julian di Giovanni, Miguel Fuentes, Botond Köszegi, Maurice Obstfeld and David Romer. Address: Diagonal Paraguay 257 Oficina 1505A, Santiago, Chile. Phone: (56)9-821-0488. E-mail: clbravo@econ.uchile.cl. 


\section{Introduction}

The lack of international diversification in the portfolios of investors all around the world is a well documented fact and has been termed the home equity bias puzzle. This lack of diversification is revealed in the high concentration in domestic equity found in any investor's portfolio around the globe. The benchmark result establishes that investors throughout the world should hold the same diversified portfolio of stocks, equivalent to holding a share of a world market mutual fund. ${ }^{1}$ Interestingly, this lack of diversification is not restricted to international portfolio allocation. There is recent evidence that shows that people tend to invest in the companies in which they are currently employed. In this manner part of their financial assets would be highly correlated with their human capital, ${ }^{2}$ thereby reducing their portfolio diversification. Before studying what can explain the home equity bias, it is important to know how big are the foregone gains of risk diversification? Lewis (2000) shows that the estimated gains that are based on stock returns are significantly higher than estimates from consumption-based models. Using stock returns the gains range from $20 \%$ to $100 \%$ of permanent consumption, while in consumption based models, as in Cole and Obstfeld (1991), gains would range from $0.04 \%$ to $5.6 \%$. This paper attempts to shed light on the role of asymmetries of information in generating the home equity bias by imposing the simplest possible informational structure on Admati's (1985) multi-asset model of noisy rational expectations.

The hypotheses that attempt to explain the home equity bias have focused empirically on the impact of asymmetries of information between domestic and foreign investors (proxied by distance, number of foreign investment banks, newspapers, phone calls), and on transaction costs. However, there have been few theoretical models explaining the relationship between asymmetric information and home equity bias. Brenan and Cao (1997) study the impact of asymmetries of information in international portfolio investment flows, while Gehrig (1993) shows that, for the case of one domestic and one foreign asset, asymmetries of information can explain the home bias.

In Gehrig's model, domestic and foreign assets' signals are uncorrelated, and domestic investors perceive foreign assets' signals with larger variance than foreign investors. Analogously, foreign investors perceive domestic assets' signals with larger variance than domestic investors. In this paper I show that by relaxing Gehrig's conditions, the existence of the home bias cannot be guaranteed. In my model the intuition can be derived from the CAPM

\footnotetext{
${ }^{1}$ For a derivation of this result see Obstfeld and Rogoff (1996).

${ }^{2}$ Heaton and Lucas (2000) and Benartzi (2001).
} 
and the concepts of good and bad hedge that are extended to an informational framework by using the fact that the demands for assets are linear in prices and signals. ${ }^{3}$ Assets' signals can increase or decrease the demands for assets over a baseline level conditional on prices. On the other hand, the increase in the signals' variance reduces the fluctuations in the demands. In this manner, domestic investors' demand for foreign assets decreases (due to the higher variance of the signals) relative to that of foreign investors for the case in which information increases the demand. Analogously, domestic investors demand more (due to the higher variance of the signals) of the foreign asset when information decreases the demand for assets. The same happens with the demands for domestic assets.

In the next section I briefly review the literature, while in the following section I introduce Admati's (1985) model. In the third section I apply the model to the case of two and three assets, and present simulations of the model. The fourth section concludes.

\section{Literature Review}

What can account for the observed lack of international risk diversification? Lewis (1999) considers three main explanations for the bias. The first postulates that home assets may provide better hedges against home country specific risks. The second suggests that the costs of diversification may outweigh the gains. The third explanation states that there are statistical measurement problems that imply there is no real home bias. Another leading explanation is based in the Salter-Swan traded-non-traded goods dichotomy. In this model investors hold a globally diversified portfolio of traded industries. But non-traded industries are held entirely domestically. More recently and in the same spirit, Obstfeld and Rogoff (2000) explore the consequences of introducing trade costs. They show that under plausible assumptions this is enough for generating a very high and realistic level of home portfolio bias. Finally, Gehrig (1993) and Brenan and Cao (1997) postulate asymmetries of information as the main determinant of the home equity bias. Recently Michaelides (2004) presents a model in which he studies the impact of "small informational costs", however these costs just correspond to transaction costs and do not follow the approach of Verrechia (1982) whose approach corresponds indeed to modeling the costs of acquiring information.

The empirical literature has built an interesting set of stylized facts that complement the theoretical explanations for the puzzle. In what follows I briefly describe the main empirical results found in the literature.

\footnotetext{
${ }^{3}$ I consider as good hedge those assets that at the optimum should be bought in positive amounts, and bad hedge those assets that at the optimum should be bought in negative amounts.
} 
Kang and Stulz (1997) find evidence for Japan in which foreign investments are skewed toward equities of large firms, for which it is believed more information is readily available. The Treasury Department (1998) also confirms this result for the case of the US. In the same spirit, Portes and Rey (2001) and Portes, Rey and Oh (2001) provide evidence that, what they call, information flows are important in cross-country equity flows. They find that gross transaction flows depend on market size on both the destination and origin country, as well as transaction costs, and distance. They control their estimates by a wide set of variables as language, currency, telephone traffic, number of bank branches and inside trading. Regarding the role of information they postulate that distance proxies some information costs, and that the number of phone calls, number of bank branches and inside trading would account by the effect of informational asymmetries.

Ahearne, Griever and Warnock (2004) find that US holdings on foreign equities are positively related to the share of the foreign country equity (directly or as American Depositary Receipts) listed on US exchanges. They relate this result to the fact that foreign firms that are listed in the US stock market are forced to provide standardized and credible financial information, reducing informational costs and hence asymmetries of information. This result is consistent with the previous finding of Kang and Stulz (1997), who establish that in the case of Japanese firms, those with ADR have more foreign ownership, although this fact was true even before the emergence of ADR's. Along these lines, Faruquee et al. (2003) find in their empirical results that market size, transaction costs and "information asymmetries" (measured by what they name information costs that include: distance, language and phone lines) are major determinants of cross border portfolio choice.

Regarding local experiences, Coval and Moskowitz (1999) find that, in the US, investment made by mutual funds also shows geographical bias. This result suggest that asymmetric information or the diffusion of information between local and non-local investors may influence investment decisions. By the same token, Hau (1999) using German data finds evidence of informational advantage for investors located close to the headquarters of the traded company in high frequency trade (intra-day).

But asymmetric information may not show up just as home equity bias. Hau (1999) also shows that foreign investors make lower profits in the German Stock market. Consistent with this result he finds weak evidence that German-speaking traders outperform non-Germanspeaking traders.

The current state of the empirical literature has not clearly differentiated between the roles of transaction costs and information acquisition costs. However, the existence of in- 
formation acquisition costs should imply asymmetries of information. Therefore, it is first needed to study whether asymmetries of information are consistent with the home equity bias, and then to study whether information costs may have an impact on it. From a theoretical perspective the only paper I am aware of in which information acquisition costs are treated separately is Verrechia (1982).

\section{Admati's Model Modified}

There is a continuum of agents distributed evenly between domestic and foreign investors. The index $\delta \in \Delta \equiv\left[0, \frac{1}{2}\right]$ counts the domestic population, while the index $\varphi \in \Phi \equiv\left[\frac{1}{2}, 1\right]$ is used for the foreign population. The agents trade in the first period and consume in the second. Each agent invests his initial wealth $W_{o i}, i \in \Delta \cup \Phi$ between a riskless asset and $n$ risky assets, $m$ of which are domestic. The riskless asset pays $R$ units and the risky assets pay $\tilde{F}$ units of the single consumption good, with the riskless asset taken as numeraire. Take the first $m$ components corresponding to the returns of the domestic equities and the remaining $(n-m)$ to the foreign equities. Let $\tilde{P}$ be the price vector of the risky assets, $\tilde{Y}_{i}$ the signal received by individual $i$ regarding the assets' returns. Therefore, we can express the demand for assets as $D_{i}\left(\tilde{P}, \tilde{Y}_{i}\right): \Re^{n} \times \Re^{n} \mapsto \Re^{n}$ the demand vector for agent $i$.

Each agent maximizes $E_{i}\left[-\exp \left(\left(W_{0 i} R+D_{i}^{\prime}(\tilde{F}-R \tilde{P})\right) / \rho_{i}\right)\right]$ conditional on his private information given by signal $\tilde{Y}_{i}$ which is correlated with $\tilde{F}$ and the equilibrium price vector $\tilde{P}$. The utility function has constant absolute risk aversion. For the sake of simplicity assume that the distribution of the risk aversion coefficients, $\rho_{i}$, in the foreign and domestic country are the same, moreover these distributions are independent of any random variable in the model. I will assume each domestic investor has a twin in the foreign country that has the same risk aversion and that perceives a signal vector i.i.d. I use this assumption in order to be able to compare the demand for assets between investors of the two countries. In this manner there is no difference in the demands due to different risk aversion coefficients.

The rational expectations hypothesis implies that each agent knows the joint normal distribution followed by $\tilde{F}, \tilde{Y}_{i}$, and $\tilde{P}$. The noise in the model comes from the random supply of equities per capita $\tilde{Z}$, which is also normally distributed. ${ }^{4}$ The noise ensures that the market price is only partially revealing. Thus, incompletely informed traders face a signal extraction problem due to the fact that prices are not a sufficient statistic for all signals in the market. If the prices where fully revealing there wouldn't be any incentive to gather

\footnotetext{
${ }^{4}$ This assumption is equivalent to impose that a fraction of the population are noisy traders
} 
information.

The private signal of individual $i$ is given by $\tilde{Y}_{i}=\tilde{F}+M_{i} \cdot \tilde{\varepsilon}_{i}, i \in \Delta \cup \Phi$, and $M_{i}$ an $n \times n$ diagonal matrix, where $\tilde{\varepsilon}_{i}$ and $\tilde{F}$ are independent and $\tilde{\varepsilon}_{i}$ has mean zero and should be independent of $\tilde{\varepsilon}_{k}, k \neq i$. I assume that signals are weakened, i.e., that on average experience a loss in precision due to the distance between the market and the origin of the investor. This fact should be interpreted as consistent with a standard deviation of signals that increases linearly with some factor $d_{i}$, that I will call fading. This is equivalent to imposing that for individual $\delta \in \Delta$ and her twin image $\varphi \in \Phi$ the error terms in their signals, $\tilde{\varepsilon}_{\delta}$ and $\tilde{\varepsilon}_{\varphi}$, should be i.i.d and the matrices $M_{\delta}$ and $M_{\varphi}$ take the form:

$$
M_{\delta}=\left[\begin{array}{cccccc}
1 & 0 & \ldots & \ldots & \ldots & 0 \\
0 & \ldots & 0 & . . & \ldots & \ldots \\
\ldots & 0 & 1 & 0 & \ldots & \ldots \\
\ldots & \ldots & 0 & d_{m+1} & 0 & 0 \\
\ldots & \ldots & \ldots & 0 & \ldots & 0 \\
0 & \ldots & \ldots & \ldots & 0 & d_{n}
\end{array}\right], M_{\varphi}=\left[\begin{array}{cccccc}
d_{1} & 0 & \ldots & \ldots & \ldots & 0 \\
0 & \ldots & 0 & \ldots & \ldots & \ldots \\
\ldots & 0 & d_{m} & 0 & \ldots & \ldots \\
\ldots & \ldots & 0 & 1 & 0 & 0 \\
\ldots & \ldots & \ldots & 0 & \ldots & 0 \\
0 & \ldots & \ldots & \ldots & 0 & 1
\end{array}\right]
$$

In the matrix $M_{\delta}$, the coefficients $d_{j}>1, j=(m+1), \ldots, n$ correspond to the different fading that faces the domestic investor in the signals of the foreign assets. Analogously, in the matrix $M_{\varphi}$, the coefficients $d_{k}>1, k=1, \ldots, m$ correspond to the fading that the foreign investor faces in the signals of domestic assets.

Note that the model does not require that an agent in the domestic country and her twin in the foreign country should receive the same signal realization. The model states that on average a domestic investor will perceive a foreign equity's signal with a loss of precision in comparison with a foreign investor. By the same token on average a foreign investor will perceive a domestic equity's signal with a loss of precision compared with a domestic investor. It is important to note that this formulation does allow foreigners to be in some cases better informed (conditional on the signal realization) than their domestic twins. Moreover, the model allows differently distributed signals for each investor in each country, and different fading coefficients between investors.

The variance covariance matrices of $\tilde{Z}, \tilde{F}, M_{i} \tilde{\varepsilon}_{i}$ are given by $U, V$ and $S_{i}$, and are assumed to be positive definite. Henceforth, and in a slight abuse of terminology I will refer the matrix $S$ as the error's covariance matrix.

The following definitions are standard in the context of noisy rational expectation models:

Definition 1 Let's consider $\left(\tilde{X}_{i}\right)_{i \in[0,1]}$ a process of independent random variables with equal 
mean, $E\left(X_{i}\right)=\bar{X}$, and $\operatorname{Var}\left(\tilde{X}_{i}\right)$ uniformly bounded. Then it is defined $\int_{0}^{1} X_{i} d i \equiv \int_{0}^{1} E\left(X_{i}\right) d i \equiv$ $\bar{X}$

This definition comes from the fact that we can rewrite $\int_{0}^{1} X_{i} d i=\int_{0}^{1}\left(\tilde{X}_{i}-E\left(X_{i}\right)\right) d i+$ $\int_{0}^{1} E\left(X_{i}\right) d i$ and due to the law of large numbers the term $\int_{0}^{1}\left(\tilde{X}_{i}-E\left(X_{i}\right)\right) d i$ is zero. This definition will allow us to identify aggregates with expected values. So whenever we take the a priori expected value (let's say for example, the difference in the demands of two individuals in an economy in which all agents have the same risk aversion ) it will correspond also to the aggregate value. ${ }^{5}$

Definition 2 A rational expectations equilibrium for the infinite economy is a price vector $\tilde{P}$ and allocation functions $D_{i}\left(\tilde{P}, \tilde{Y}_{i}\right)_{i \in[0,1]}$ such that:

(a) $\tilde{P}$ is $(\tilde{F}, \tilde{Z})$ measurable;

(b) $D_{i}\left(\tilde{P}, \tilde{Y}_{i}\right) \in \operatorname{argmax}_{D_{i}} E\left(u_{i}\left(\tilde{W}_{1, i}\right) \mid \tilde{P}, \tilde{Y}_{i}\right)$;

(c) $\int_{0}^{1} D_{i}\left(\tilde{P}, \tilde{Y}_{i}\right) d i=\tilde{Z}$ almost surely.

From Corollary 3.4 of Admati (1985) the demands for equities are given by the equation:

$$
D_{i}\left(\tilde{Y}_{i}, \tilde{P}\right)=G_{0 i}+G_{1 i} \tilde{Y}_{i}-G_{2 i} \tilde{P}
$$

where $i$ corresponds to the origin of the investor and the matrices are given by:

$$
\begin{aligned}
& G_{1 i}=\rho_{i} S_{i}^{-1} \\
& G_{2 i}=\rho_{i}\left(A_{2}^{-1}-R \bar{\rho} Q+R S_{i}^{-1}\right) \\
& G_{0 i}=\rho_{i}\left(I-\left(U Q^{-1}+\bar{\rho} I\right)^{-1}\right)\left(V^{-1} F+Q U^{-1} \tilde{Z}\right)
\end{aligned}
$$

Where $\mathrm{Q}$ is given by

$Q=\int_{0}^{1 / 2} \rho S_{h}^{-1} d h+\int_{1 / 2}^{1} \rho_{f} S_{f}^{-1} d f=\frac{1}{2}\left(S_{h}^{-1}+S_{f}^{-1}\right)$, where $h$ indexes the domestic population and $f$ the foreign population.

and $A_{2}=\frac{1}{R}\left(\bar{\rho} V^{-1}+\bar{\rho} Q U^{-1} Q+Q\right)^{-1}\left(I+\bar{\rho} Q U^{-1}\right)$ with $\bar{\rho}$ the average risk aversion in the global economy.

Therefore, we can rewrite the demand of individual $i$ as follows:

$$
E\left[D_{i}\right]=\rho \cdot S_{i}^{-1}(\bar{F}-R \bar{P})+K(V, Q, U, \bar{Z})
$$

In what follows, I will call $K(V, Q, U, Z)$ baseline level and, $S_{i}^{-1}(\bar{F}-R \bar{P})$ informational effect.

In order to explain the home equity bias one needs to analyze the difference in the demands of the domestic and foreign investors. Therefore, I will compare the demand of a

\footnotetext{
${ }^{5}$ This is because the random variables have the same mean.
} 
given domestic investor with the demand of her mirror image in the foreign country. Thus, the discussion in the following section up to the simulations will only analyze the existence of the bias on the demands of these two individuals. Consequently, it seems to be appropriate to consider that the impact of the changes on the demands (due to fading) of these two investors have zero impact on prices. Moreover, the impact of the changes in the demands of two individuals will not have an impact on the clearing market condition; this will happen because this condition can be expressed as $\int_{0}^{1} D_{i}\left(\tilde{P}, \tilde{Y}_{i}\right) d i=\tilde{Z}$ almost surely and these changes in demands have measure zero. However, if we analyze the impact of changes in fading for the case of a common informational effect for all the investors in a given country there will be changes in prices and on the baseline level so that the clearing market condition holds. In section 3, simulations will consider the overall impact of the informational structure on the prices given a common informational structure among investors of each country.

As will be noted, the results in the following sections will depend on whether the excess return of the assets is positive or negative. In what follows I only consider the case in which all excess returns are positive. The reader should reverse the conclusions for the case in which all assets present negative excess returns.

\subsection{One Foreign Asset and One Domestic Asset.}

In this section I study the role of asymmetries of information for the case of one domestic and one foreign asset. The loss of precision in the signals between the origin of the signal and the origin of the investor does not need to be symmetric.

Because there is one foreign asset and one domestic asset and two different possible levels of fading, the signals' errors covariance matrix for the domestic and foreign investor are given respectively by: ${ }^{6}$

$$
\begin{aligned}
& S_{d}=\left(\begin{array}{cc}
S_{11} & S_{12} \cdot d_{2} \\
S_{21} \cdot d_{2} & S_{22} \cdot d_{2}^{2}
\end{array}\right) \\
& S_{f}=\left(\begin{array}{cc}
S_{11} \cdot d_{1}^{2} & S_{12} \cdot d_{1} \\
S_{21} \cdot d_{1} & S_{22}
\end{array}\right)
\end{aligned}
$$

First, I must identify the terms in the demands for equities that depend on the origin of the investor. It is straightforward to note that $G_{1 i}$ depends totally on the origin of the investor through the matrix $S_{i}^{-1}$. While for $G_{2 i}$ note that the only term that depends on

\footnotetext{
${ }^{6}$ Similar results to the ones derived in this section can be obtained by assuming that $S_{d}^{-1}$ and $S_{f}^{-1}$ correspond to the average inverse matrix of the signal's covariance matrix.
} 
the origin of the investor is $\left(S_{i}^{-1}\right)$. Therefore, the impact that signals have on demand is the opposite to that of prices.

Thus the net effect of the weakening in the signal on the demand for equities depends on the excess of return as follows:

$$
\rho_{i} S_{i}^{-1} \tilde{Y}-\rho_{i} R S_{i}^{-1} \tilde{P}=\rho_{i} S_{i}^{-1}(\tilde{Y}-R \tilde{P})
$$

Next, use the superscripts $d, f$ in order to denote the vector components related to each type of equity, and the subscripts to identify the origin of the investor. Finally, the expected difference in the demands for domestic and foreign equity between a domestic investor and a foreign investor with the same risk aversion can be expressed as follows:

$$
\begin{aligned}
& E\left[D_{d}^{d}-D_{f}^{d}\right]=\frac{\rho_{i}}{D}\left[S_{22}\left(F^{d}-R P^{d}\right)\left(1-\frac{1}{d_{1}^{2}}\right)+S_{12}\left(F^{f}-R P^{f}\right)\left(-\frac{1}{d_{2}}+\frac{1}{d_{1}}\right)\right] \\
& E\left[D_{d}^{f}-D_{f}^{f}\right]=\frac{\rho_{i}}{D}\left[S_{21}\left(F^{d}-R P^{d}\right)\left(-\frac{1}{d_{2}}+\frac{1}{d_{1}}\right)+S_{11}\left(F^{f}-R P^{f}\right)\left(\frac{1}{d_{2}^{2}}-1\right)\right]
\end{aligned}
$$

with $D=S_{11} S_{22}-S_{12} S_{21}$.

Note that, as intuition suggests, the difference in the demands between domestic and foreign investors is originated solely in the asymmetries of information.

If the covariance between the signals' errors is zero, the home equity bias for assets with positive excess of return is obtained. The same happens if $d_{1}=d_{2}$. I must note that Gehrig (1993) assumes zero covariance between the signals' errors and equal fading among assets ensuring in this way the existence of the home bias on the demands of these two individuals. However, as will be shown this result is not as general as suggested.

Note that if the fading coefficient were proportional to the distance between the origin of the investor and the origin of the asset, one would obtain the traditional gravitational model for the difference in the expected demands for assets. ${ }^{7}$ Now, for the more general case in which fading is different for different assets $d_{1}>d_{2}$ the home equity is reinforced for the case of the foreign equity, but is weakened for the domestic equity when $S_{21}$ is greater than zero. The opposite happens when $S_{21}$ is smaller than zero.

The intuition of this result can be derived by assuming that the two assets have the same positive excess of return and that their signals' errors covary positively. If $d_{1}>d_{2}$ it is harder to get signals of good quality regarding domestic equity for foreign investors than for domestic ones. Domestic investors and foreign investors will tend to buy less of each equity, as indicated by the second terms in the difference in the demand for the domestic

\footnotetext{
${ }^{7}$ This assumption would imply $d_{1}=d_{2}$
} 
equity and the first term for the foreign equity. ${ }^{8}$ Due to the fading in the signals, domestic investors will perceive a larger positive correlation between assets than that perceived by foreigners, and will buy less of the domestic equity than the foreigners, thereby inducing a less pronounced home bias for the domestic asset. Regarding the foreign asset, an analogous result is obtained in which domestic investors perceive again a greater correlation between signals' errors. Thus, they buy more of the foreign asset, increasing the home bias for the foreign asset.

Finally, if the signals' errors covary negatively, the home bias is increased in the case of the domestic equity but decreases in the case of foreign equity. The fact that $S_{12}$ is smaller than zero increases the demands for both assets. Due to the larger fading that foreign investors face, they do not perceive both assets as good hedges like foreigners do, so foreign investors increase their demand for both assets to a lesser extent. This implies that the bias is increased for the domestic equity but decreases for the foreign.

Note that the assumption that $d_{1}$ and $d_{2}$ are different must not be disregarded as a peculiarity. Indeed, it is likely to be the case that an investor from a third world country can follow more closely the American economy than non-sophisticated Americans can follow a third world economy in which there is less information readily available.

Next, assume that $d_{2}=1$, and note now that the difference in the demands for the foreign equity just depends on the covariance term. Thus, if the covariance is greater than zero there exists a home bias reversal in which domestic investors buy more of the foreign equity than foreigners do. Therefore, for the case in which domestic and foreign investors face different fading levels and the covariance between signals' errors is different from zero, asymmetric information is not merely consistent with home bias but also with its reversal. In the next subsection I generalize this result and provide further intuition.

In the next section I study whether zero covariance between signals' errors or equal fading among assets are sufficient conditions for explaining the home equity bias.

\subsection{Two Foreign Assets and One Domestic}

As an intermediate step towards a more general conclusion, I consider one domestic asset and two foreign assets. As before I assume that each asset has its own and particular level of fading in its signal.

\footnotetext{
${ }^{8}$ If we analyze the impact of changes in fading for the case of a common informational effect for all the investors in a given country there will be changes in prices and on the baseline level so that the clearing market condition holds.
} 
In this case the signals' errors covariance matrix for the domestic investor is given by:

$$
S_{d}=\left(\begin{array}{ccc}
S_{11} & S_{12} \cdot d_{2} & S_{13} \cdot d_{3} \\
S_{21} \cdot d_{2} & S_{22} \cdot d_{2}^{2} & S_{23} \cdot d_{2} \cdot d_{3} \\
S_{31} \cdot d_{3} & S_{32} \cdot d_{2} \cdot d_{3} & S_{33} \cdot d_{3}^{2}
\end{array}\right)
$$

While for the foreign investor:

$$
S_{f}=\left(\begin{array}{ccc}
S_{11} d_{1}^{2} & S_{12} d_{1} & S_{13} d_{1} \\
S_{21} d_{1} & S_{22} & S_{23} \\
S_{31} d_{1} & S_{32} & S_{33}
\end{array}\right)
$$

I use the superscripts $d, f_{i}$ in order to denote the vector components related to each type of equity. The difference in the demands for the different equities can be expressed as follows:

$$
\begin{gathered}
E\left[D_{d}^{d}-D_{f}^{d}\right]=\frac{\rho_{i}}{D}\left[\begin{array}{c}
\left(S_{22} S_{33}-S_{23} S_{32}\right)\left(F^{d}-R P^{d}\right)\left(1-\frac{1}{d_{1}^{2}}\right)+ \\
+\left(S_{13} S_{32}-S_{12} S_{33}\right)\left(\frac{1}{d_{2}}-\frac{1}{d_{1}}\right)\left(F^{f_{1}}-R P^{f_{1}}\right)+ \\
+\left(S_{12} S_{23}-S_{13} S_{22}\right)\left(\frac{1}{d_{3}}-\frac{1}{d_{1}}\right)\left(F^{f_{2}}-R P^{f_{2}}\right)
\end{array}\right] \\
E\left[D_{d}^{f_{1}}-D_{f}^{f_{1}}\right]=\frac{\rho_{i}}{D}\left[\begin{array}{c}
\left(S_{31} S_{23}-S_{21} S_{33}\right)\left(F^{d}-R P^{d}\right)\left(\frac{1}{d_{2}}-\frac{1}{d_{1}}\right)+ \\
+\left(S_{11} S_{33}-S_{31} S_{13}\right)\left(F^{f_{1}}-R P^{f_{1}}\right)\left(\frac{1}{d_{2}^{2}}-1\right)+ \\
+\left(S_{21} S_{13}-S_{11} S_{23}\right)\left(F^{f_{2}}-R P^{f_{2}}\right)\left(\frac{1}{d_{2} d_{3}}-1\right)
\end{array}\right] \\
E\left[D_{d}^{f_{2}}-D_{f}^{f_{2}}\right]=\frac{\rho_{i}}{D}\left[\begin{array}{c}
\left(S_{21} S_{32}-S_{31} S_{22}\right)\left(F^{d}-R P^{d}\right)\left(\frac{1}{d_{3}}-\frac{1}{d_{1}}\right)+ \\
+\left(S_{12} S_{31}-S_{11} S_{32}\right)\left(F^{f_{1}}-R P^{f_{1}}\right)\left(\frac{1}{d_{2} d_{3}}-1\right)+ \\
+\left(S_{11} S_{22}-S_{21} S_{12}\right)\left(F^{f_{2}}-R P^{f_{2}}\right)\left(\frac{1}{d_{3}^{2}}-1\right)
\end{array}\right]
\end{gathered}
$$

with $D=S_{11} S_{22} S_{33}-S_{11} S_{23} S_{32}-S_{21} S_{12} S_{33}+S_{21} S_{13} S_{32}+S_{31} S_{12} S_{23}-S_{31} S_{13} S_{22}$

In the next subsections I study three cases with three different set of assumptions in order to find out whether there are conditions under which asymmetries of information explain the home bias. These set of assumptions covers all possible informational structures.

\subsubsection{Zero Covariance Between Signals' Errors}

I now analyze the simplest case. To begin, assume that the covariances between the signals' errors is zero. Then the expected differences in the demands can be expressed as follows:

$$
\begin{gathered}
E\left[D_{d}^{d}-D_{f}^{d}\right]=\rho_{i}\left[S_{11}\left(F^{d}-R P^{d}\right)\left(1-\frac{1}{d_{1}^{2}}\right)\right] \\
E\left[D_{d}^{f_{1}}-D_{f}^{f_{1}}\right]=\rho_{i}\left[S_{22}\left(F^{f_{1}}-R P^{f_{1}}\right)\left(\frac{1}{d_{2}^{2}}-1\right)\right]
\end{gathered}
$$




$$
E\left[D_{d}^{f_{2}}-D_{f}^{f_{2}}\right]=\rho_{i}\left[S_{33}\left(F^{f_{2}}-R P^{f_{2}}\right)\left(\frac{1}{d_{3}^{2}}-1\right)\right]
$$

In this case, there exists a home bias for the three equities as long as the excess returns are positive. Note that the expected differences for each equity also depend on the variance of the asset and the fading coefficient on the signals associated with each asset. Thus the larger the variance of the asset the larger the bias. In the same manner the larger the fading coefficient the larger the bias. As in the case for two assets, if the fading coefficient is proportional to the distance between the origin of the investor and the origin of the asset, I recover the traditional gravitational model for the difference in the expected demands for assets. So in short, zero covariance between signals' errors does guarantee the home equity bias.

\subsubsection{Uncorrelated Signals' Errors Between Domestic and Foreign Assets}

As a second exploration into the sufficient conditions that guarantee the home bias, assume now that the correlation between the domestic and the foreign equities' signals' errors is zero. This implies that $S_{12}=S_{21}=S_{13}=S_{31}=0$. For the sake of simplicity I also assume that the variances of all signals errors are 1 . The bias for the domestic equity can be expressed as follows:

$$
\begin{aligned}
E\left[D_{d}^{d}-D_{f}^{d}\right] & =\frac{\rho_{i}}{D}\left[\left(S_{22} S_{33}-S_{23} S_{32}\right)\left(F^{d}-R P^{d}\right)\left(1-\frac{1}{d_{1}^{2}}\right)\right] \\
& =\frac{\rho_{i}}{D}\left(1-r_{23}^{2}\right)\left(F^{d}-R P^{d}\right)\left(1-\frac{1}{d_{1}^{2}}\right)
\end{aligned}
$$

With $D=1-r_{23}^{2}$, I recover directly the home bias for a domestic equity with positive excess return.

On the other hand I can rewrite the expected difference in the demands for the first of the foreign equity (equation (6)) as follows:

$$
E\left[D_{d}^{f_{1}}-D_{f}^{f_{1}}\right]=\frac{\rho_{i}}{D}\left[\left(F^{f_{1}}-R P^{f_{1}}\right)\left(\frac{1}{d_{2}^{2}}-1\right)+S_{23}\left(F^{f_{2}}-R P^{f_{2}}\right)\left(-\frac{1}{d_{2} d_{3}}-(-1)\right)\right]
$$

So home bias is recovered for the first foreign equity whenever $S_{23}$ is smaller than zero, given positive excess return. Suppose for now that $d_{2}=1$ so that the sign of the bias depends totally on the sign of $S_{23}$. For the case $S_{23}>0$ foreign investors want to diversify 
their portfolios and want to buy less of the foreign equities. ${ }^{9}$ However, because of the fading in the signals, domestic investors perceive a weaker covariance in the signal's error than the actual one. Therefore, they tend to reduce to a lesser extent their purchases of the first of the foreign equities generating a home equity bias reversal, in which domestic investors buy more of the foreign equity. For the case $S_{23}<0$, foreign investors want to diversify their portfolios, buying more of both foreign assets. Because of the fading in the signals, domestic investors perceive a weaker covariance and tend to buy less, in relative terms, of the foreign equity. In this manner the traditional home bias exists for the first of the foreign equities.

By the same token, rewrite the expected difference in the demands for the second of the foreign equity (equation (7)) as follows:

\footnotetext{
${ }^{9}$ The fact that $S_{23}<0$ implies a higher demand for both assets may not be straightforward and intuitive. So let's illustrate this fact with an example. Let's take:

$Y_{1}=F_{1}+\epsilon_{1}$

$Y_{2}=F_{2}+\epsilon_{2}$

the real returns of assets 1 and 2 . With each one of the random variables distributed in the following manner $\left(\begin{array}{c}F_{1} \\ F_{2}\end{array}\right) \sim N\left(\left(\begin{array}{c}\bar{F} \\ \bar{F}\end{array}\right),\left(\begin{array}{cc}1 & -1 \\ -1 & 1\end{array}\right)\right)$ and $\left(\begin{array}{c}\epsilon_{1} \\ \epsilon_{2}\end{array}\right) \sim N\left(\left(\begin{array}{l}0 \\ 0\end{array}\right),\left(\begin{array}{cc}\sigma_{\epsilon_{1}}^{2} & \sigma_{\epsilon_{1} \epsilon_{2}} \\ \sigma_{\epsilon_{1} \epsilon_{2}} & \sigma_{\epsilon_{2}}^{2}\end{array}\right)\right)$
}

Therefore for the portfolio $W_{t+1}=W_{t}+W_{t}\left(x_{1} Y_{1}+x_{2} Y_{2}\right)$ has mean and variance given by $E\left[W_{t}+W_{t}\right.$. $\left.\left(x_{1} Y_{1}+x_{2} Y_{2}\right)\right]=W_{t} \cdot(1+\bar{F})$ and $\operatorname{Var}\left[W_{t}+W_{t}\left(x_{1} Y_{1}+x_{2} Y_{2}\right)\right]=W_{t}^{2}\left(x_{1}^{2} \sigma_{\epsilon_{1}}^{2}+x_{2}^{2} \sigma_{\epsilon_{2}}^{2}+x_{1} x_{2} 2 \sigma_{\epsilon_{1}} \epsilon_{2}\right)$

To solve for the optimal portfolio, is equivalent to maximize $W_{t+1} \prime=W_{t}+W_{t} \cdot\left(x_{1} Z_{1}+x_{2} Z_{2}\right)$ with $\left(\begin{array}{c}Z_{1} \\ Z_{2}\end{array}\right) \sim$ $N\left(\left(\begin{array}{c}F \\ F\end{array}\right),\left(\begin{array}{cc}\sigma_{\epsilon_{1}}^{2} & \sigma_{\epsilon_{1} \epsilon_{2}} \\ \sigma_{\epsilon_{1} \epsilon_{2}} & \sigma_{\epsilon_{2}}^{2}\end{array}\right)\right)$

For a consumer with CARA utility function this maximization problem can be expressed as follows: $\operatorname{Max}_{x_{1}, x_{2}} E\left[U\left(W^{\prime}\right)\right]$ where $E\left[U\left(W^{\prime}\right)\right]=\int_{-\infty}^{\infty}-\exp \left(-\rho W^{\prime}\right) \cdot f\left(W^{\prime}\right) d W^{\prime}=-\exp \left(\rho\left(E\left[W^{\prime}\right]-\frac{\rho}{2} \operatorname{Var}\left[W^{\prime}\right]\right)\right)$

Therefore, the problem reduces to maximize the certainty equivalent but under this setup this is equal to solve the CAPM model. And we know the CAPM model demands for assets can be expressed as follows: Defining $\rho^{\prime}=-2 \frac{\rho}{2} W^{\prime}$

$$
\begin{aligned}
\left(\begin{array}{l}
x_{1} \\
x_{2}
\end{array}\right) & =\rho^{\prime}\left(\begin{array}{cc}
\sigma_{\epsilon_{1}}^{2} & \sigma_{\epsilon_{1} \epsilon_{2}} \\
\sigma_{\epsilon_{1} \epsilon_{2}} & \sigma_{\epsilon_{2}}^{2}
\end{array}\right)^{-1} \cdot\left(\begin{array}{c}
F \\
F
\end{array}\right) \\
& =\rho^{\prime} \frac{1}{\sigma_{\epsilon_{1}}^{2} \sigma_{\epsilon_{2}}^{2}-\sigma_{\epsilon_{1} \epsilon_{2}}^{2}}\left(\begin{array}{cc}
\sigma_{\epsilon_{2}}^{2} & -\sigma_{\epsilon_{1} \epsilon_{2}} \\
-\sigma_{\epsilon_{1} \epsilon_{2}} & \sigma_{\epsilon_{1}}^{2}
\end{array}\right) \cdot\left(\begin{array}{c}
F \\
F
\end{array}\right) \\
& =\rho^{\prime} \frac{F}{\sigma_{\epsilon_{1}}^{2} \sigma_{\epsilon_{2}}^{2}-\sigma_{\epsilon_{1} \epsilon_{2}}^{2}}\left(\begin{array}{c}
\sigma_{\epsilon_{2}}^{2}-\sigma_{\epsilon_{1} \epsilon_{2}} \\
\sigma_{\epsilon_{1}}^{2}-\sigma_{\epsilon_{1} \epsilon_{2}}
\end{array}\right)
\end{aligned}
$$

Therefore, conditional on diversification (this is minimizing the variance of the portfolio as the CAPM does) the demands for each one of the assets is increasing on the covariance between the errors when the covariance is negative. Then, for $S_{23}$, positive diversification implies buying less of each asset. 


$$
E\left[D_{d}^{f_{2}}-D_{f}^{f_{2}}\right]=\frac{\rho_{i}}{D}\left[S_{32}\left(F^{f_{1}}-R P^{f_{1}}\right)\left(-\frac{1}{d_{2} d_{3}}-(-1)\right)+\left(F^{f_{2}}-R P^{f_{2}}\right)\left(\frac{1}{d_{3}^{2}}-1\right)\right]
$$

The home bias exists for the second of the foreign equity whenever $S_{23}$ is smaller than zero. If $S_{23}$ is greater than zero there will be home bias whenever $S_{32}\left(F^{f_{1}}-R P^{f_{1}}\right)\left(-\frac{1}{d_{2} d_{3}}+1\right)<$

$\left(F^{f_{2}}-R P^{f_{2}}\right)\left(-\frac{1}{d_{3}^{2}}+1\right)$. The term that depends on $S_{32}$ has the same interpretation as the one that was provided in the previous paragraph.

\subsubsection{Equal Fading Among Assets}

Now analyze the more general case in which the signals' errors covary and the fading of all assets are equal, i.e., $d_{1}=d_{2}=d_{3}=d$. Under these circumstances it is straightforward to note that for the domestic asset the bias will always exist given that:

$$
\left(S_{22} S_{33}-S_{23} S_{32}\right)\left(F^{d}-R P^{d}\right)>0
$$

For the first of the foreign equities the condition needed for the home equity bias to exist is given by:

$$
\left(S_{11} S_{33}-S_{31} S_{13}\right)\left(F^{f_{1}}-R P^{f_{1}}\right)\left(\frac{1}{d^{2}}-1\right)+\left(S_{11} S_{23}-S_{21} S_{13}\right)\left(F^{f_{2}}-R P^{f_{2}}\right)\left(1-\frac{1}{d^{2}}\right)<0
$$

or equivalently

$$
\left[\left(S_{11} S_{33}-S_{31} S_{13}\right)\left(F^{f_{1}}-R P^{f_{1}}\right)-\left(S_{11} S_{23}-S_{21} S_{13}\right)\left(F^{f_{2}}-R P^{f_{2}}\right)\right]>0
$$

Now analyze the case in which $S_{11}=S_{22}=S_{33}=1$, the covariance $S_{13}$ is close to one and $S_{21}=0$. It can be noted that the first term of the last inequality will be arbitrarily small, while that the second term will be $-\left(S_{23}\right)\left(F^{f_{2}}-R P^{f_{2}}\right)$. Thus, if $S_{23}$ is smaller than zero the home bias will be recovered, while if $S_{23}$ is greater than zero a bias reversal will happen.

For the second foreign equity the condition for the home bias to hold is given by

$$
\left(S_{11} S_{32}-S_{12} S_{31}\right)\left(F^{f_{1}}-R P^{f_{1}}\right)\left(-\frac{1}{d_{2}^{2}}+1\right)+\left(S_{11} S_{22}-S_{21} S_{12}\right)\left(F^{f_{2}}-R P^{f_{2}}\right)\left(\frac{1}{d_{2}^{2}}-1\right)<0
$$

or equivalently,

$$
\left(S_{11} S_{32}-S_{12} S_{31}\right)\left(F^{f_{1}}-R P^{f_{1}}\right)-\left(S_{11} S_{22}-S_{21} S_{12}\right)\left(F^{f_{2}}-R P^{f_{2}}\right)<0
$$


Thus, under the same conditions of the analysis carried out for the first foreign equity, it can be noted that if $S_{32}$ is smaller than zero we recover the home bias, while if $S_{23}$ is greater than zero the bias reversal can not be ensured, depending on the relation of the excess of return.

In summary, information can either increase or decrease the demand for assets. When asymmetries of information are considered, it is clear that the home equity bias will arise whenever the role of information is to increase the demand for assets. For the case of the foreign asset, domestic investors face a lack of precision in their signals compared with the foreign investors. However, in this case the lack of precision does not change the nature of the role played by information. Thus information will increase the demand for assets for both types of investors. The difference arises in the magnitude of the increase in the demands. As intuition suggests, domestic investors will demand the foreign equity to a lesser extent. On the other hand, when information decreases the demand for assets, the lack of precision will reduce the domestic investors' demand for assets to a lesser extend generating home equity bias reversals in the demand for foreign equity.

\subsection{Interpretation}

From the previous section it should be clear that the simplest case for grasping some intuition corresponds to the common fading case. Therefore, the following results will apply to this case. ${ }^{10}$ Inspired in the demand for assets derived from the CAPM I define informational good and bad hedges. ${ }^{11}$

Definition 3 Good Informational Hedge: those assets for which informational effect increases their demands over thebaseline level. This is for individual $i$ and asset $j$ it holds that:

$$
\left[S_{i}^{-1}\right]_{\text {row }_{j}} \cdot(F-R P)>0
$$

Definition 4 Bad Informational Hedge: those assets for which informational effect decreases their demands over the baseline level. This is for individual $i$ and asset $j$ it holds

\footnotetext{
${ }^{10}$ This result can be generalized to the case of multiples fadings in which $d_{1}>d_{2}, d_{1}>d_{3}$. For the complementary case this set of results does not generalize.

${ }^{11}$ The demand for Assets in the CAPM model is given by: $\chi=\rho^{-1} \cdot \Omega^{-1} \cdot r$ with $\Omega$ the returns covariance matrix. In our case: $E\left[D_{i}\right]=\rho \cdot S_{i}^{-1}(F-R P)+K(V, Q, U, Z)$ with $\mathrm{K}(\mathrm{V}, \mathrm{Q}, \mathrm{U}, \mathrm{Z})$ the baseline level of demand. Furthermore, $E\left[D_{d}-D_{f}\right]=\left(S_{d}^{-1}-S_{f}^{-1}\right) \cdot(F-R P)$
} 
that:

$$
\left[S_{i}^{-1}\right]_{\text {row }_{j}} \cdot(F-R P)<0
$$

From the previous subsection it is clear that the following result will hold:

Proposition 1 Assets that are good informational hedges will show home bias, while those assets that are bad informational hedges will show home bias reversals.

The intuition underlaying the proposition is that the fading will smooth the perceptions of domestic and foreign investors. Let's take the case of a domestic investor considering buying a foreign asset. For the case of a good informational hedge, the domestic investor will perceive it as less of a good hedge than foreign investors, demanding less of it as a result. For the case of a bad informational hedge, the domestic investor will perceive it as less of a bad hedge than foreign investors, demanding more of it as a result.

\subsection{Simulations}

So far I have analyzed from a theoretical point of view the implications of asymmetric information on the home equity bias in the demands of two individuals. In this section, I illustrate the possibility of the home equity bias reversals implementing simulations of the model.

The theoretical approach considered the impact of asymmetries of information on the individual demands for a pair of agents, holding prices constant. The simulations will consider the impact of the asymmetries of information on the price of the assets as well. To this end, I assume that all agents in each country face the same informational effect (they have a common matrix $S_{i}$ ). Each agent faces the fading in the signals related to their respective foreign equities.

By using Definition 1 we obtain that the difference in the aggregate demands for assets between countries is given by: $E\left[D_{d}-D_{f}\right]=\bar{\rho} \cdot\left(S_{d}^{-1}-S_{f}^{-1}\right) \cdot(\bar{F}-R \bar{P})$ where $\bar{\rho}$ corresponds to the average risk aversion in the global economy.

Following Admati (1985), I will consider that the excess return for the assets can be expressed as $(F-R P)=\left(\bar{\rho} V^{-1}+\bar{\rho} Q U^{-1} Q+Q\right)^{-1} Z$, where the matrix $Q$ captures the aggregate informational structure of the model.

The simulations will first illustrate the impact of different fading levels on the second foreign asset's signal, fixing the level of fading of the domestic and the first foreign equity at 1. This is done in order to isolate the impact of asymmetric information of one asset on each one of the demands, thus facilitating the analysis. 
The covariance matrices, the vector of endowments and the mean of the assets returns are:

$$
\begin{aligned}
& S=\left(\begin{array}{lll}
2 & 0 & 0 \\
0 & 1 & 1 \\
0 & 1 & 2
\end{array}\right) ; V=\left(\begin{array}{ccc}
20 & 0 & 0 \\
0 & 30 & 20 \\
0 & 20 & 40
\end{array}\right) ; U=\left(\begin{array}{ccc}
20 & 0 & 0 \\
0 & 20 & 0 \\
0 & 0 & 20
\end{array}\right) \\
& Z=\left(\begin{array}{l}
100 \\
100 \\
100
\end{array}\right) ; F=\left(\begin{array}{l}
400 \\
250 \\
450
\end{array}\right)
\end{aligned}
$$

The risk aversion coefficient is 1 . The value of the matrices and vectors were selected so that the initial shares of the portfolios of the domestic and foreign investors allocated on their own home equities were $50 \%$.

First we must note is that despite the fact the analysis primarily focus on the impact of changes on the fading of the second foreign asset, there will be changes in prices and demands for the first of the foreign assets. However, the price and the demand for the domestic asset will remain constant as intuition suggest for the case of symmetric information. The difference in the demands for the domestic asset is expressed in equation (5). The fact that $d_{1}$ is equal to one cancels the first term that is due to the symmetric information on the first asset, while the second and third term are zero due to the fact that $S_{12}$ and $S_{13}$ are zero. This implies that the contribution of the variance of the foreign assets to the demand for the domestic asset is zero. If there are no changes in demands there will be no changes in prices.

Fading in the signal of the second foreign equity shifts the demand of the domestic country towards the first foreign equity, decreasing the demand for the second foreign equity. Regarding the foreign demand, there is an increase in the demand for the second equity and a decrease in the demand for the first foreign equity. The previous changes in demand give origin to home bias in the case of the second foreign equity and a home bias reversal for the case of the first foreign equity. The intuition behind the reversal phenomena for a given level fading is that both foreign equities signals' errors are positively correlated so information diminishes the demands of both types of investors (see equation (13)). For a given level of fading, domestic investors perceive a lower correlation on the errors than foreign investors do. This leads domestic investors to diminish their demand for the equity less than foreigners do, causing in this way a bias reversal. Consistent with this fact, domestic investors demand increases with the fading, while the demand of foreign investors decrease; this generates an increase in the reversal given an increase in the fading. Figure 1 shows the bias and its 
Figure 1: Home Equity Bias and its reversal

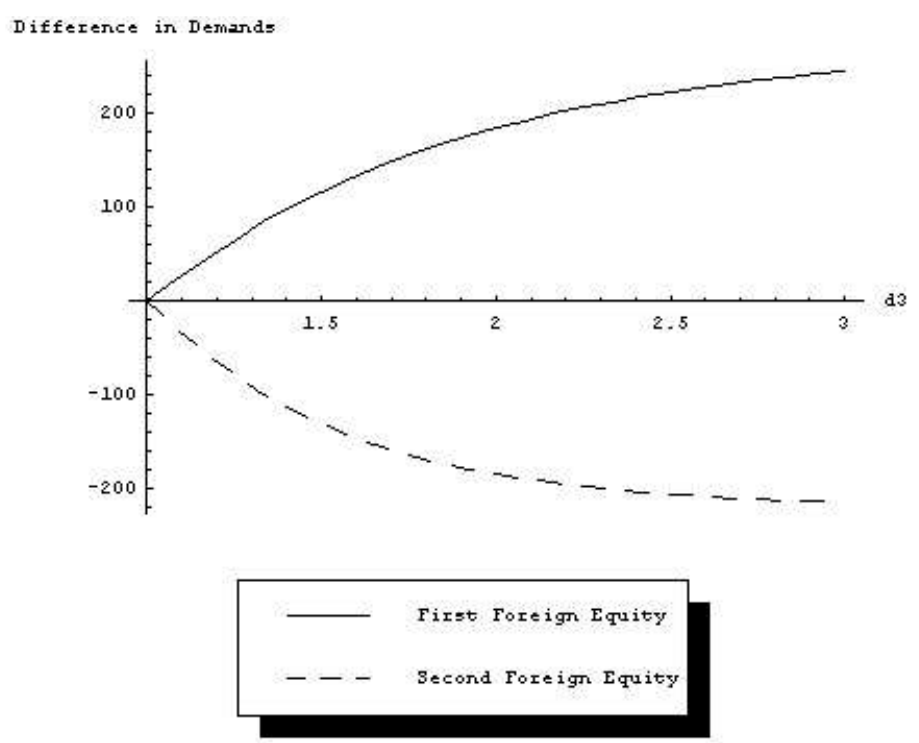

reversal.

According to the changes in the domestic and foreign demands for the two foreign assets we observe an increase in the price of the first foreign equity and a decrease in the price of the second foreign equity. These results are consistent with the intuition that worse information may reduce the price of some assets. Figure 2 shows the price dependence on the level of fading.

According to the previous behavior of demands and prices it is possible to analyze the changes that experience the share of the investors' portfolio allocated to home equity, $H_{i}$, $i \in\{f, d\}$. The share $H_{i}$, for domestic and foreign investors are defined by:

$$
\begin{aligned}
& H_{d}=\frac{D_{d}^{d} P^{d}}{D_{d}^{d} P^{d}+D_{d}^{f_{1}} P^{f_{1}}+D_{d}^{f_{2}} P^{f_{2}}} \\
& H_{f}=\frac{D_{f}^{f_{1}} P^{f_{1}}+D_{f}^{f_{2}} P^{f_{2}}}{D_{f}^{d} P^{d}+D_{f}^{f_{1}} P_{1}^{f_{1}}+D_{f}^{f_{2}} P^{f_{2}}}
\end{aligned}
$$

As I mentioned before, the price and the demands for the domestic asset remain constant despite the changes on the fading of the second foreign asset. This elicits the fact that changes on $H_{d}$ will be obtained as a consequence of changes in the portfolio shares allocated into the first and the second foreign assets. We already know there is an increase in demand of the domestic country for the first foreign equity and a decrease in the demand for the second foreign equity. This together with the fact that the price of the first foreign equity 
Figure 2: Equity Prices and Asymmetric Information

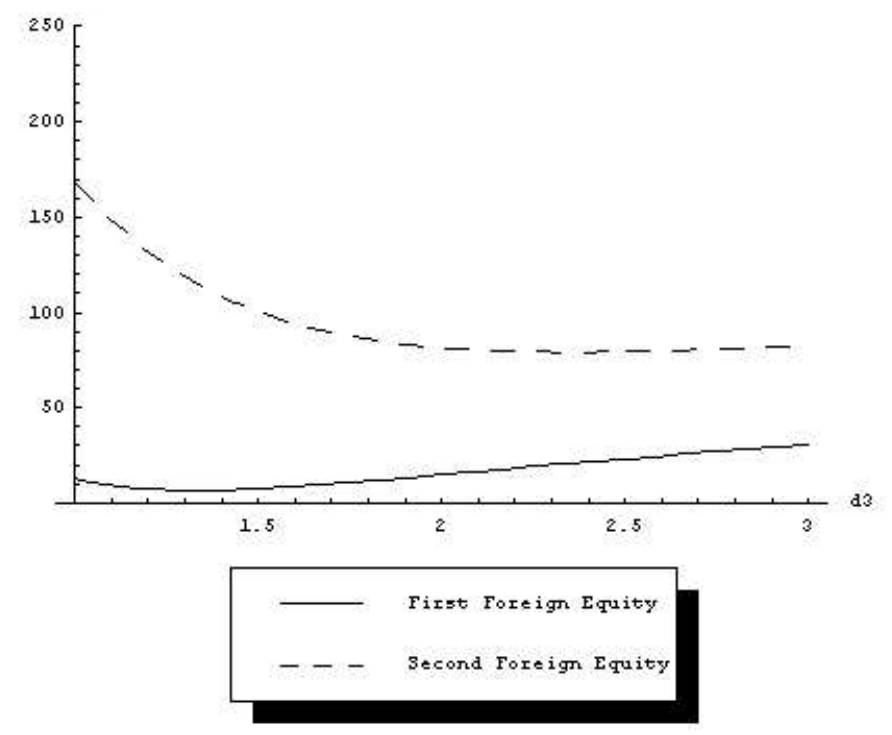

decreases and then increases and the price of the second foreign equity decreases, will imply an initial increase in $H_{d}$ and then a decrease. That is, $H_{d}$ initially increases because the value of the portfolio allocated in both foreign assets decreases. Then $H_{d}$ decreases because the value of the portfolio allocated on the first foreign equity increases faster than the decrease in the value of the portfolio allocated on the second foreign asset.

Given that the foreign demand for the second equity increases, the demand for the first foreign equity decreases, and that the price of the first foreign equity increase and the price of the second foreign equity decreases, $H_{f}$ will first decrease as the value of the portfolio allocated in both foreign equities decrease and will then increase as the foreign investor's portfolio concentrates in the second foreign equity. Figure 3 shows the behavior of $H_{d}$ and $H_{f}$.

The simulation exercise shows us that once we consider the impact of the fading into assets prices the main predictions derived in the first half of this paper are still valid. Therefore, asymmetries of information are not a consistent explanation for the home bias puzzle. 
Figure 3: Country Home Bias and its reversal

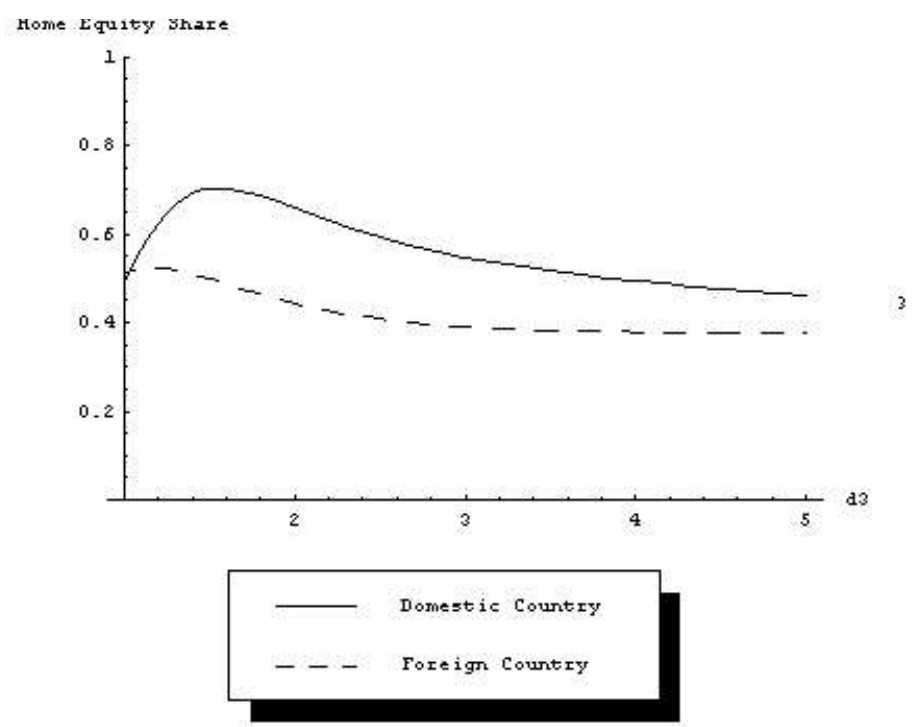

\section{Conclusion}

Contradicting conventional wisdom, this paper shows that asymmetries of information can not explain the existence of the home equity bias. The asymmetries of information can only guarantee the home equity bias when all assets signals' errors are uncorrelated among them. The model presented in the paper also predicts the existence of home equity bias reversals as a consequence of asymmetries of information. These results show that although asymmetric information may be one of the phenomena lying behind the home bias, it is not enough to explain it by itself.

The results shown in this paper invite a reexamination the existing empirical evidence. Part of this evidence postulates that distance proxies some information costs, and that the number of phone calls and number of bank branches would account for the effect of informational asymmetries. Based on the results of this paper and in light of the work of Obstfeld and Rogoff (2000), these variables seem to be good proxies for transport costs between countries, which under plausible assumptions are enough for generating a very high and realistic level of home portfolio bias.

Further research is needed to address the evidence that shows that size of the firms or the existence of ADR's matter for foreign ownership. Most likely these issues should be 
addressed on the grounds of corporate finance.

Finally, if information acquisition costs and asymmetries of information were one of the explanations for the home bias, further theoretical research should be needed to address these issues with a novel approach.

\section{References}

Admati, Anat, "A Noisy Rational Expectations Equilibrium for Multi Asset Securities Markets," Econometrica, 1985, 53.

Ahearne, Alan, William Griever, and Francis Warnock., "Information Costs and Home Bias: An Analysis of U.S. Holdings of Foreign Equities," Journal of International Economics, 2004, 62, 313-336.

Benartzi, Shlomo, "Excessive Extrapolation and the Allocation of 401(k) Accounts to Company Stock?," Journal of Finance, October 2001, 56 (5), 1747-64.

Brennan, Michael and Henry Cao, "International Porfolio Investment Flows," Journal of Finance, December 1997, 52 (5), 1851-1880.

Cole, Harold and Maurice Obstfeld, "Commodity Trade and International Risk Sharing: How Much Do Financial Markets Matter?," Journal of Monetary Economics, August 1991, 28 (1), 3-24.

Coval, Joshua and Tobias Moskowitz, "Home Bias at Home: Local Equity Preference in Domestic Portfolios," Journal of Finance, December 1999, 54 (6), 2045-2073.

Faruquee, Hamid, Shijing Li, and Isabel Yan, "The determinants of International Portfolio Holdings and Home Bias," February 2004. IMF Working Paper.

French, Kenneth and James M. Poterba, "Behavioral Finance Investor Diversification and International Equity Markets," American Economic Review, May 1991, 81 (2), 222-226. Papers and Proceedings of the Hundred and Third Annual Meeting of the American Economic Association.

Gehrig, Thomas, "An Information Based Explanation of the Domestic Bias in International Equity Investment," Scandinavian-Journal-of-Economics, 1993, 95 (1), 97-109. 
Hau, Harald, "Location Matters: An Examination of Trading Profits," The Journal of Finance, October 2001, 56 (5), 1959-1983.

Heaton, John and Deborah Lucas, "Portfolio Choice and Asset Prices: The Importance of Entrepreneurial Risk?," Journal of Finance, June 2000, 55 (3), 1163-1198.

Kang, Jun-Koo and Rene Stultz, "Why is there a home bias? An analysis of foreign portfolio equity ownership in Japan," Journal of Financial Economics, October 1997, $46(1), 3-28$.

Lewis, Karen, "Why Do Stocks and Consumption Imply Such Different Gains from International Risk Sharing?," Journal of International Economics, October 2000, 52 (1), $1-35$.

Michaelides, Alexander, "International Portfolio Choice, liquidity constraints and the home equity bias puzzle," Journal of Economic Dynamics and Control, 2003, 28, 555-94.

Obstfeld, Maurice and Kenneth Rogoff, Foundations of International Macroeconomics, MIT Press, 1996.

_ and _ _ "The Six Major Puzzles in International Macroeconomics: Is There a Common Cause?," July 2000. NBER Working Paper.

Portes, Richard and Helene Rey, "The Determinants of Cross-Border Equity Flows," July 2001. Draft.

Portes, Richard Helene Rey and Yonghyup Oh, "Information and Capital Flows: The determinants of transactions in financial assets," European Economic Review, May 2001, $45(4), 783-96$.

Tesar, Linda and Ingrid Werner, "Home bias and high turnover," Journal of International Money and Finance, August 1995, 14 (4), 467-492.

Verrechia, Robert, "Information Acquisition in a Noisy Rational Expectations Economy," Econometrica, November 1982, 50 (6), 1415-30.

Warnock, Francis, "Home Bias and High Turnover Reconsidered," April 2001. International Finance Discussion Papers , N 702, Board of Governors of the Federal Reserve System. 